\title{
Measurement of volume change in cemented mine backfills at early ages
}

\section{T. Belem Université du Québec en Abitibi-Temiscamingue, Canada}

A.B. Fourie The University of Western Australia, Australia

M. Fahey The University of Western Australia, Australia

\begin{abstract}
In this paper, the dilatometry (or volumetric method) was use for direct measurements of the chemical shrinkage of cemented mine backfill (CMB). This test follows an ASTM standard test protocol and is very simple to conduct. For the first time, the results of direct measurements of volume reduction in CMB were obtained. These results confirm that the higher water-to-cement ratios in CMB lead to less efficiency of the hydration reactions at early age. This method can be used routinely to assess and understand the short term hydration processes in $C M B$.
\end{abstract}

\section{Introduction}

Early age ( $\leq 48$ hours) volume change/reduction or chemical shrinkage (i.e. endogenous deformation) in cementitious matrices refers to the observation that the volume of the hydrates produced by the reaction between unhydrated cement and water is smaller than the total volume of the cement and water. Volume change is the result of several complex physico-chemical phenomena, which are related to the hydration reactions between cement and water and to the progressive hardening of the mineral skeleton or stiffness development (Justnes et al., 1994). At very early age and during setting, two phenomena are directly responsible for the shrinkage of cementitious material in undrained conditions: capillary depression in the porous space and Le Chatelier's contraction (Bouasker et al., 2008). In cemented mine backfill (CMB), evidence of chemical shrinkage (called self-desiccation) has been observed through the measurement of pore water pressure dissipation or matric suction increase due to capillary depression (Grabinsky and Simms, 2006; Fourie et al., 2006; Helinski et al., 2007; Witteman and Simms, 2010). Therefore, the hydration reactions reduce the total volume of initial water, increase the stiffness of CMB solid phase, and increase the ultimate strength. One aspect that has not been studied as of yet, is to directly measure the chemical shrinkage in CMB as a combined effect of capillary depression and Le Chatelier's contraction. The main objective of this study is to undertake direct measurement of volume change in CMB in order to allow making a link with pore pressure dissipation during curing.

\section{Background on volume change}

\subsection{Volume change in cementitious materials}

It should be noted that endogenous shrinkage (also called hydration shrinkage) is caused by Le Chatelier's contraction that produces voids (capillary empty pores) in the hydrated cement paste. These capillary empty pores have the effect of reducing the internal relative humidity of a sealed system and this process is called self-desiccation. This occurs when chemical shrinkage takes place at the stage when the paste matrix has developed a self-supportive skeleton (Acker, 2004). Therefore, self-desiccation describes one of the two phenomena responsible for the volume change in cementitious material as previously mentioned. Le Chatelier's contraction is explained by the density difference between hydrates on the one hand, and cement and water on the other hand. At complete hydration, this contraction can represent approximately $10 \%$ of the initial volume of the material. However, the material rarely exhibits such a high deformation because the progressive stiffness development resists this chemical shrinkage (Bouasker et al., 2008). Experimental assessments of chemical shrinkage usually give a value in the range of $0.05-0.06 \mathrm{~cm}^{3} / \mathrm{g}$ of cement, which is in fact $7-8 \%$ of total volume (Powers and Brownyard, 1948). The experimentally observed shrinkage 
depends both on the chemical composition of the cement and its fineness (Beltzung and Wittmann, 2000; Bentz et al., 2008). During hardening, water adsorbs onto and adsorbs within the ettringite mineral; as it does, the net volume of the cement decreases (Skoblinskaya and Krasilnikov, 1975). Although ettringite formation does cause expansion, the net volumetric effect is chemical shrinkage because of the formation of many other shrinkage-type crystals (Chenevert and Shrestha, 1991). It is generally agreed that cement chemical shrinkage is a volume change phenomenon associated with the removal of free water from the cement mixture (Powers, 1968; Felman and Sereda, 1968). Bensted (1983) showed the importance of water in cement chemical shrinkage. He noted that increasing the water content of the cement slurry increased ettringite formation and the amount of cement chemical shrinkage. He suggested that these effects were caused by additional water aiding in the dissolution and transport of calcium and sulphate ions to the aluminate and ferrite phases. Indeed, Beltzung and Wittmann (2000) found that early chemical shrinkage is due to at least two very different mechanisms: i) volume change by dissolution of cement components, and ii) water consumption by hydration. In cement and concrete, volume change is measured for cement pastes having a water-to-cement ratio $(w / c)$ varying from 0.35 to 0.6 . However, for CMB the $w / c$ ratio usually varies from 3 to 20 (Belem and Benzaazoua, 2007) depending on whether the mixture is cemented paste backfill (CPB) or cemented slurry fill (CSF). From the standpoint of texture, these mixtures are water saturated and are therefore considered as cement pulps rather than cement pastes, because there is more water than is necessary for hydration.

Levine et al. (1979) showed that under laboratory conditions, hydrostatic pressures can decrease in a column of cement as it sets. In these tests, the cement columns had no outlets for filtration (undrained conditions), thus showing that chemical shrinkage alone can reduce hydrostatic pressure. Cooke et al. (1983) performed field measurements and showed that a $57 \%$ decrease in hydrostatic pressure is possible. They used pressure transducers to measure cement pressures in a $\sim 2,743 \mathrm{~m}$ well and showed that the bottom hole pressure (BHP) decreased from $\sim 50 \mathrm{MPa}(7,200 \mathrm{psi})$ to $\sim 28 \mathrm{MPa}(4,100 \mathrm{psi})$ in 7.6 hours, i.e. $43 \%$ reduction or $-2.8 \mathrm{MPa} / \mathrm{hr}$. Recently, it was observed from undrained laboratory tests that by backpressuring CPB and CSF samples containing $5 \mathrm{wt} \%$ cement up to $500 \mathrm{kPa}$, the process of chemical shrinkage reduced the pore pressures after 65 hours by about $32 \%$ for $\mathrm{CPB}$ and $64 \%$ for $\mathrm{CHF}$. It has been concluded that chemical shrinkage positively influenced the development of effective stress, which plays a big role in mechanical strength development within CMB (Helinski et al., 2007). No direct measurement of chemical shrinkage was performed on CMB materials.

\subsection{Measurement methods}

Le Chatelier first observed that hydration of cement caused a reduction in the absolute volume of a cement paste. Early chemical shrinkage results were used to quantify the extent of chemical reaction that had taken place. For example, Powers and Brownyard (1948) used measurements of chemical shrinkage (called absorption) as an index to the progress of the reactions. Knudsen and Geiker (1982) related chemical shrinkage with compressive strength development, but the primary objective of any chemical shrinkage test is to quantify the change in volume that occurs due to the hydration reactions. The chemical shrinkage is generally quantified by measuring the amount of water that is sorbed by a saturated cement paste (Parrot et al., 1990). The chemical shrinkage test enables water to enter the system after the structure is formed (i.e. it is an open system) and measures the total volume change of the cement paste (Sant et al., 2006). Justnes et al. (2000) listed three principal measurement methods of Le Chatelier's contraction: dilatometry (change in volume), pycnometry (change in weight) and gravimetry (change in buoyancy). The principles of the three methods are illustrated in Figure 1 (Bouasker et al., 2008). Among these test methods, the most widely used remains dilatometry. The dilatometry method is generally based on the change of water level in a capillary tube above a paste specimen (Geiker, 1983). While this test method is economical, it is time consuming because the height of the water needs to be measured at regular intervals (Sant et al., 2006). Moreover, this test is difficult to automate although methods like the use of a photoelectric cell have been described by Buil (1979). Pycnometry and gravimetry are based on the change in density (or buoyancy) that occurs when water is absorbed in the hydrating specimen. Many authors have used the dilatometry method to study the influence of the cement composition, the $w / c$ ratio, the presence of pozzolanic additions and polymer additives on the evolution of chemical shrinkage (Bouasker et al., 2008). This paper utilises dilatometry measurements that are described in detail later. 


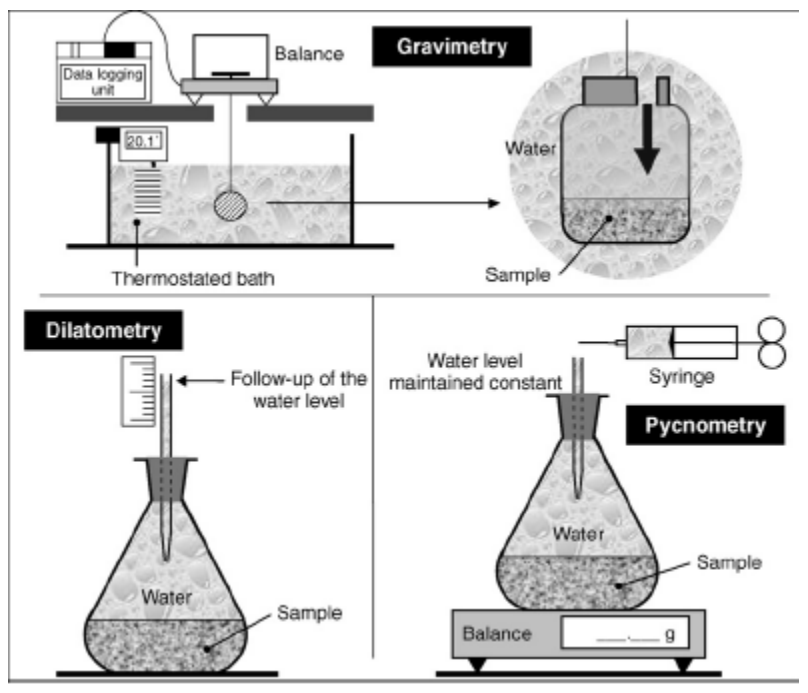

Figure 1 Chemical shrinkage measurement methods (after Bouasker et al., 2008)

\subsection{Factors affecting volume change measurements}

It should be noted that, however apparently simple, these listed chemical shrinkage test methods have several experimental difficulties that can result in spurious results (Sant et al., 2006). First, the thickness of the specimen (Boivin et al., 1998; Geiker, 1983) influences the results, since thicker specimens (especially specimens with a low $w / c$ ) develop a low porosity and water cannot travel fast enough to fill in the vaporfilled voids created by chemical shrinkage. In addition, the water on the surface of the specimen could have a different chemistry than the fluid in the pores, possibly resulting in leaching. Variations in the sample temperature that occur during hydration may also influence results, especially if the samples are large. Garcia-Boivin (1999) showed theoretically and experimentally the equivalence of the results obtained by dilatometry and gravimetry. Therefore, with a simple experimental device such as gravimetry (see Figure 1), it allows to record automatic and continuous measurements of chemical shrinkage. Powers (1935) investigated the chemical shrinkage of cement pastes varying in the water-cement ratio showing that an increase in the water-cement ratio is accompanied by an increase in absorption. The same effect of water-tocement ratio on chemical shrinkage was found by Czernin (1962). The influence of the temperature on chemical shrinkage at early stages has been investigated by Hansen et al. (1968). The chemical shrinkage (in their paper named volume contraction) of cement pastes with water-cement ratio of 0.5 was measured at four different temperatures $\left(25,45,60\right.$, and $\left.80^{\circ} \mathrm{C}\right)$ between 0 and 24 hours. As expected, increased temperature caused an increase in the rate of development of chemical shrinkage.

\subsection{Modelling chemical shrinkage}

\subsubsection{Model of chemical shrinkage as a function of degree of hydration}

Powers and Brownyard (1948) proposed a relationship between the chemical shrinkage $\Delta V_{\mathrm{cs}}$ and the degree of hydration $\alpha$ as follows:

$$
\Delta V_{c s}(\alpha)=\frac{\alpha\left(1-v_{n}\right) \cdot \frac{w_{n}}{c}}{v_{c}+\frac{w}{c}}=\frac{0.25^{2} \alpha}{0.32+\frac{w}{c}}
$$

Where:

$\begin{array}{ll}\Delta V_{\mathrm{cs}} & =\quad \text { chemical shrinkage }\left(\mathrm{cm}^{3} / \mathrm{g} \text { of cement }\right) \text { measured at degree of hydration } \alpha . \\ v_{\mathrm{n}} & =\quad \begin{array}{l}\left(\approx 0.75 \mathrm{~cm}^{3} / \mathrm{g}\right)=\text { specific volume of the chemically bound water, which means that the } \\ \text { chemical shrinkage equals up to } 25 \% \text { of the volume of the chemically bound water } v_{\mathrm{n}} .\end{array} \\ w_{\mathrm{n}} & =\quad\left(\approx 0.32 \mathrm{~cm}^{3} / \mathrm{g}\right)=\text { specific volume of cement. }\end{array}$


$w / c \quad=\quad$ water-to-cement ratio.

From Equation (1), the degree of hydration can be approximated as follows:

$$
\alpha(t)=\Delta V_{c s}(t) \frac{0.32+\frac{w}{c}}{0.25^{2}}
$$

\subsubsection{Model of chemical shrinkage as a function of time}

Geiker and Knudsen (1982) developed a mathematical model to describe the development of chemical shrinkage $\Delta V_{\mathrm{cs}}$ as a function of time $t$ given as follows:

$$
\Delta V_{c s}=\Delta V_{c s(\infty)} \frac{\left(t-t_{0}\right)}{\left(t-t_{0}\right)+t_{50}}=\Delta V_{c s(\infty)} \frac{\Delta t}{\Delta t+t_{50}}
$$

Where:

$$
\begin{array}{lll}
\Delta V_{\mathrm{cs}} & = & \text { chemical shrinkage measured at time } t\left(\mathrm{~cm}^{3} / 100 \mathrm{~g} \text { of cement }\right) . \\
\Delta V_{\mathrm{cs}(\infty)} & = & \begin{array}{l}
\text { chemical shrinkage at 'infinite time' }\left(\mathrm{cm}^{3} / 100 \mathrm{~g}\right. \text { of cement) which should corresponds to } \\
100 \% \text { hydration. }
\end{array} \\
t_{0} & = & \text { duration of the dormant period or setting time (minute or hour); } \Delta t=\text { time after initial set. } \\
t_{50} & = & \text { reaction time }\left(t-t_{0}\right) \text { necessary to reach } \Delta V_{\mathrm{cs}(\infty)} / 2 \text { (minute or hour). }
\end{array}
$$

According to the authors, this model fits data for $\Delta V_{\mathrm{cs}} / \Delta V_{\mathrm{cs}(\infty)}>0.10$ (low water-to-cement ratios).

\subsubsection{Model of chemical shrinkage for saturated cement slurry}

Beltzung and Wittmann (2000) proposed a model for quantifying the absolute chemical shrinkage of saturated cement slurry. This model was built on the assumption that early chemical shrinkage, or absolute volume reduction $\Delta V_{\text {sh }}$ of the slurry, should be subdivided into 'dissolution shrinkage' $V_{\mathrm{dc}}$ and 'hydration shrinkage' $V_{\mathrm{hc}}$ which occur simultaneously, given as follows:

$$
\Delta V_{s h}=V_{d c}+V_{h c}=C_{s} V_{w}+V_{h c}=C_{s}\left[(w / c) \cdot \rho_{c} \cdot V_{c} / \rho_{w}\right]+V_{h c}
$$

and

$$
\Delta V_{s h} / V_{c}=C_{s}\left[(w / c) \cdot \rho_{c} / \rho_{w}\right]+\left(V_{h c} / V_{c}\right)
$$

Where:

$$
\begin{array}{lll}
C_{\mathrm{s}} & = & \text { cement concentration at saturation (solubility). } \\
V_{\mathrm{w}} & = & \text { volume of water }\left(\mathrm{cm}^{3}\right) . \\
w / c & = & \text { water-to-cement ratio. } \\
V_{\mathrm{c}} & = & \text { initial volume of cement concentration at saturation }\left(\mathrm{cm}^{3}\right) . \\
\rho_{\mathrm{c}}, \rho_{\mathrm{w}} & = & \text { specific density of cement grains and water, respectively }\left(\mathrm{g} / \mathrm{cm}^{3}\right) .
\end{array}
$$

Knowing $C_{\mathrm{s}}$ and $V_{\mathrm{hc}} / V_{\mathrm{c}}$ allows prediction of absolute or relative volume reductions. Experimental results showed that the constants $C_{\mathrm{s}}$ and $V_{\mathrm{hc}} / V_{\mathrm{c}}$ depend on cement chemical composition and fineness. The dissolution shrinkage $V_{\mathrm{dc}}$ is supposed to take place before as well as after the induction (or dormant period). In fact, immediately after mixing cement and water very little hydration occurs (Bonett and Pafitis 1996). In the meanwhile, the paste is not 'dormant' with respect to volume changes since several authors report very early shrinkage during induction period (Damidot and Nonat, 1991). Benzaazoua et al. (2004) described twostages hardening process in CMB materials: dissolution and hydration (stage I) and precipitation and hydration (stage II). 


\subsubsection{Model of self-desiccation for CMB materials}

Helinski et al. (2007) use an exponential maturity function $m$ (Illiston et al., 1979) to propose a model of prediction of the 'net water volume reduction' $\Delta V_{\mathrm{hyd}}\left(=\Delta V_{\mathrm{w}} / W_{\mathrm{c}}\right)$ in CMB material. In reality, this corresponds to the chemical shrinkage volume $\Delta V_{\text {cs }}$, due to 'self-desiccation' process. This model is given as follows:

$$
\Delta V_{h y d}=\Delta V_{w} / W_{c}=\Delta V_{s h} / W_{c}=E_{h} \cdot \exp \left(-\frac{d}{\sqrt{t-t_{0}}}\right)=\Delta V_{c s}
$$

Where:

$$
\begin{array}{lll}
\Delta V_{\mathrm{w}} & = & \text { net water volume reduction }\left(\mathrm{cm}^{3}\right) . \\
W_{\mathrm{c}} & = & \text { mass of unhydrated cement }(\mathrm{g}) . \\
E_{\mathrm{h}} & = & \text { 'efficiency' parameter }\left(\mathrm{cm}^{3} / \mathrm{g}\right)=\text { total volume change that occurs during hydration. } \\
d & = & \text { maturity constant }(\sqrt{ } \text { day }) . \\
t_{0}, t & = & \text { time at initial set and total elapsed time, respectively (day); } \Delta t=t-t_{0}=\text { time after initial }
\end{array}
$$

This model is similar to Equation (3), where $E_{\mathrm{h}}$ is comparable to $\Delta V_{\mathrm{cs}(\infty)}$ and the exponential term to the hyperbolic function of time. These two models given by Equations (3) and (6) are considering that when $t=t_{0}$, i.e. before initial set (or during the dormant period) there is no chemical shrinkage $\left(\Delta V_{\mathrm{cs}}=0\right)$. However, this assumption is in disagreement with the observation that neat cement paste is not 'dormant' with respect to volume changes since several authors report very early shrinkage during induction period ( Damidot and Nonat, 1991; Sent et al., 2006; Bouasker et al., 2008). From Equation (6), Helinski et al. (2007) proposed the rate of volume change per unit mass of hydrated cement, given as follows:

$$
\frac{\delta\left(\Delta V_{h y d}\right)}{\delta t}=\frac{\delta\left(\Delta V_{w} / W_{c}\right)}{\delta t}=\frac{\delta\left(\Delta V_{s h} / W_{c}\right)}{\delta t}=0.5 \cdot E_{h} \cdot \frac{d}{\Delta t^{1.5}} \cdot \exp \left(-\frac{d}{\sqrt{\Delta t}}\right)=\frac{\delta\left(\Delta V_{c s}\right)}{\delta t}
$$

In order to predict the incremental change in the pore water pressure (or dissipation) $\Delta u$ due to the chemical shrinkage volume $\Delta V_{\text {hyd }}$ or $\Delta V_{\text {sh }}$, Helinski et al. (2007) proposed the following model:

$$
\Delta u=-\frac{\Delta V_{s h}}{V_{w} V_{T}} \cdot \frac{K_{w} K_{s}}{\left(\frac{K_{s}}{V_{T}}+\frac{K_{w}}{V_{w}}\right)}=-\frac{\Delta V_{s h}}{V_{T}} \cdot \frac{K_{w}}{\left(n+\frac{K_{w}}{K_{s}}\right)}
$$

Where:

$$
\begin{array}{lll}
V_{\mathrm{w}}, V_{\mathrm{T}} & = & \text { current total volume of the pore water and total or bulk volume }\left(\mathrm{cm}^{3}\right), \text { respectively. } \\
K_{\mathrm{w}}, K_{\mathrm{s}} & = & \text { bulk moduli of water and soil skeleton }(\mathrm{MPa} \text { or GPa), respectively. } \\
n & = & \text { total porosity of the material. }
\end{array}
$$

\subsubsection{Simplified Helinski et al. (2007) pore pressure dissipation model}

Equation (8) can be rewritten in the following form:

$$
\Delta u=-\frac{\Delta V_{s h}}{V_{T}\left(\frac{n}{K_{w}}+\frac{1}{K_{s}}\right)}=-\frac{\Delta n}{n\left(\frac{n}{K_{w}}+\frac{1}{K_{s}}\right)}
$$

As the bulk modulus of water, $K_{\mathrm{w}} \approx 2.2 \mathrm{MPa}$ (Lide, 1997) which must be an order of magnitude higher than that of the CMB skeleton (tailings) $K_{\mathrm{s}}$, the above Equation (9) can be simplified as follows $\left(n / K_{\mathrm{w}} \approx 0\right)$ :

$$
\Delta u=-\left(\frac{\Delta n}{n}\right) K_{s}=-\left(\frac{\Delta V_{s h}}{V_{T}}\right) K_{s}=-\left(\frac{\Delta e}{1+e_{0}}\right) K_{s}
$$


Where:

$\Delta n \quad=\quad$ change in porosity $n$.

$e_{0}, \Delta e \quad=\quad$ initial void ratio and in change in initial void ratio.

\section{$3 \quad$ Material and method}

\subsection{Material}

A silt-size tailings from Kanowna Belle (KB) mine, which is located close to Kalgoorlie in WA, Australia, was used for volume change testing of cemented backfill. Grain size distribution (GSD) shows that this tailings contains $50 \%$ of fine grains (particle size $<20 \mu \mathrm{m}$ ) and that $d_{10}=3 \mu \mathrm{m}, d_{30}=8 \mu \mathrm{m}, d_{50}=20 \mu \mathrm{m}$, $d_{60}=32 \mu \mathrm{m}$ and $d_{90}=200 \mu \mathrm{m}$. From these parameters, the uniformity coefficient $C_{\mathrm{U}}\left(=d_{60} / d_{10}\right)$ and the coefficient of curvature $C_{\mathrm{C}}\left(=d_{30}{ }^{2} / d_{60} \times d_{1}\right)$ can be calculated. In the United Soil Classification System (USCS), well-graded soil requires $C_{\mathrm{C}}$ to be in the range 1-3, and $C_{\mathrm{U}}>6$. For expected 'good' quality CMB, the tailings sample must be well graded. For the KB material, the values of the uniformity coefficient $C_{\mathrm{U}}$ and coefficient of curvature $C_{\mathrm{C}}$ are 10.7 and 0.67 , respectively. Consequently, KB material is classified as finegrained material in the USC system and is considered as poorly graded. The specific gravity $G_{\mathrm{s}}$ of KB tailings is 2.72. General use Portland cement (Type GU) from Cockburn Cement (Perth, Western Australia) was used.

\subsection{Method}

As stated above, early age hydration rates can be provided by chemical shrinkage measurements of the cement paste during its hydration (Powers, 1935; Geiker and Knudsen, 1982). Since 2005, a standard testing procedure has been developed by the American Standard of Testing and Materials (ASTM) for both dilatometry (volumetry) and pycnometry (density methods) chemical shrinkage tests (ASTM, 2007). The method relies on the assumption that all contraction pores are filled with water, which probably is correct at this early age and with such a thin sheet of cement slurry (Justnes et al., 2000). In this paper, the dilatometry or volumetric method only was used. The protocol described in the following section follows the ASTM description of the procedure.

\subsubsection{Chemical shrinkage measurement protocol}

The equipment used for measurements were $1.0 \mathrm{~mL}$ capacity graduated glass capillary tubes with graduations of $0.01 \mathrm{~mL}, 119.5 \mathrm{~mL}$ plastic vials $(39 \mathrm{~mm}$ diameter and $100 \mathrm{~mm}$ height), and rubber stoppers with central hole. The graduated capillary tubes were first, inserted through the rubber stopper holes and sealed with silicone grease applied at the stopper's top and bottom surfaces. The cement paste, slurry or $\mathrm{CMB}$ is prepared in a $500 \mathrm{~mL}$ Erlenmeyer flask by hand mixing with a teaspoon.

The standard paste mixture uses $150 \mathrm{~g}$ of cement and $60 \mathrm{~mL}$ of water (water-cement ratio $w / c=0.40$ ). The ASTM (2007) standard allows other water-cement ratios to be used $(w / c=0.35,0.7,7.0,11.12,12.69$ and 13.5 in the present paper) as long as they are reported. Higher water-cement ratios may produce significant bleeding of the cement paste, which will influence the results (by changing the effective water-cement ratio, etc.); lower water-cement ratios may lead to difficulties in preparing a fully compacted, homogeneous paste for subsequent evaluation and self-desiccation may occur.

After determining the mass of each empty plastic vial, cement paste, slurry or CMB was placed into the $119.5 \mathrm{~mL}$ plastic vial to achieve a specimen thickness of $10 \mathrm{~mm}$. A minimum of two replicate specimens were used for each test. The paste in the vial was consolidated by tapping the vial on the laboratory countertop and then placed under vacuum for 20-30 minutes to remove all residual air bubbles. The mass of specimen was determined by differential weighting to the nearest $0.01 \mathrm{~g}$.

The remaining empty volume was then carefully filled with de-aired water, without disturbing the specimen, to the top. The rubber stopper with the inserted capillary tube was placed tightly into the plastic vial, carefully avoiding the entrapment of air bubbles when the bottom rubber stopper surface encountered the water in the plastic vial. As the rubber stopper was inserted, the water level in the graduated capillary tube 
rises. Optimally, the water level should rise near to but not beyond the top mark of the graduations on the capillary tube.

A drop of paraffin oil was placed in the top of the graduated capillary tube to minimise water evaporation from the tube during the testing period (see Figure 2).

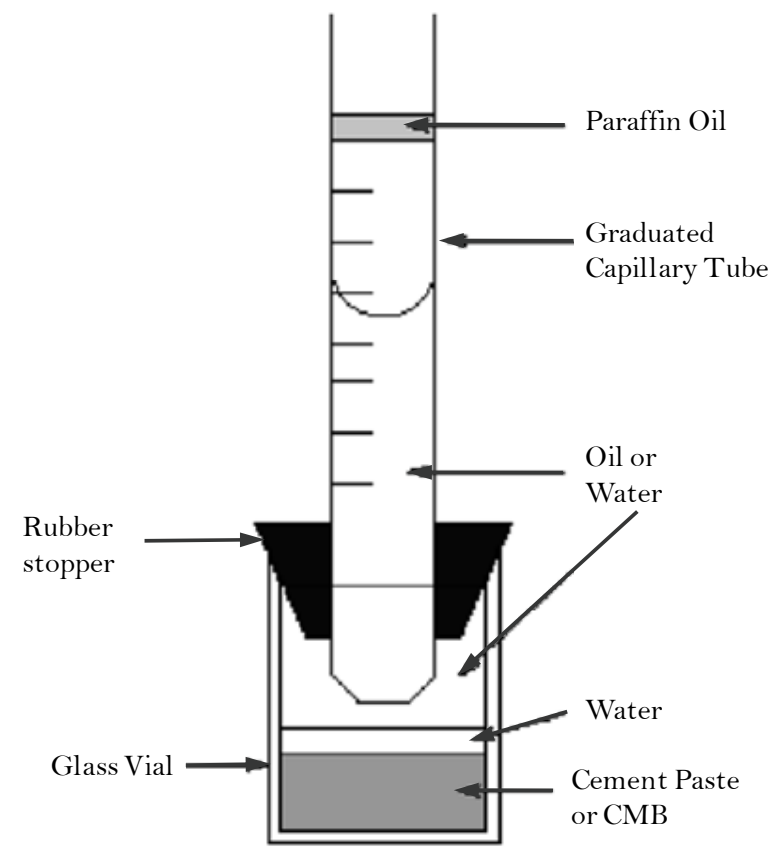

Figure 2 Illustration of experimental setup for monitoring chemical shrinkage of hydrating cement paste (adapted from ASTM, 2007)

The prepared specimens were placed in the constant temperature water bath at $23^{\circ} \mathrm{C}$ such that the tops of the plastic vials are just above the water level in the bath. The temperature of the laboratory was maintained at $23 \pm 2{ }^{\circ} \mathrm{C}$. The time and initial level (height) of water was recorded, to the nearest $0.0025 \mathrm{~mL}$, in the capillary tubes. Periodically (every $30 \mathrm{~min}$ or every hour), the time (to the nearest minute) and water level (meniscus) in the capillary tubes (to the nearest $0.0025 \mathrm{~mL}$ ) were recorded for a total period of at least $24 \mathrm{hr}$. After the first $8 \mathrm{hr}$, the recording intervals were lengthened to $8 \mathrm{hr}$ or more to avoid taking readings during the night, as long as a $24 \mathrm{hr}$ reading was obtained the following day. A reading was taken one hour after the paste was first mixed to use as a zero point in all calculations (this allows time for the specimen to achieve temperature equilibrium within the water bath). The chemical shrinkage $C S(t)$ or $\Delta V_{\mathrm{sh}}(t)$, was computed as the measured volume $(\mathrm{mL})$ of sorbed water per gram of cement $\left(\mathrm{mL} / \mathrm{g}\right.$ or $\left.\mathrm{cm}^{3} / \mathrm{g}\right)$ in the specimen. For cement paste or slurry, the mass of cement in the plastic vial $M_{\mathrm{cem}}$ is given by:

$$
M_{c e m}=\frac{M_{\text {vial }+ \text { sample }}-M_{\text {vial_empty }}}{(1.0+w / c)}=\frac{M_{\text {sample }}}{(1.0+w / c)}
$$

And for cemented mine backfill the mass of cement in the plastic vial $M_{\mathrm{cem}}$ is given by:

$$
M_{\text {cem }}=\frac{M_{\text {sample }}\left(1-\frac{1}{1+B_{w}}\right)}{1+w_{\text {sample }}}=\frac{M_{\text {sample }}\left(1-\frac{1}{1+C \% /(100-C \%)}\right)}{1+w_{\text {sample }}}=\frac{M_{\text {sample }}\left(1-\frac{1}{1+C \% /(100-C \%)}\right)}{1+\left(100-C_{w \%}\right) / C_{w \%}}
$$

Where:

$M_{\text {vial+paste }}=\quad$ mass of the glass vial with the added cement paste (g).

$M_{\text {vial_empty }}=$ mass of the empty vial $(\mathrm{g})$.

$M_{\text {sample }}=\quad$ mass of the specimen (cement paste/slurry or CMB) in the vial (g). 


$$
\begin{aligned}
& w / c \quad=\quad \text { water-to-cement ratio by mass of the prepared specimen (e.g. 0.40) and a density of } \\
& 1 \mathrm{~g} / \mathrm{cm}^{3} \text { is assumed for water. } \\
& B_{\mathrm{w}} \quad=\quad \text { fractional binder/cement content by dry mass of tailings }\left(=M_{\text {cement } / \text { binder }} / M_{\text {dry }} \text { tailings }\right) \text {. } \\
& C \% \quad=\quad \text { cement content by dry mass of solids }\left(=100 \times M_{\text {cement }} /\left[M_{\text {cement }}+M_{\text {dry_tailings }}\right]\right) \text {. } \\
& w_{\text {sample }}=\quad \text { fractional gravimetric water content of the specimen (cement paste/slurry or CMB). } \\
& C_{\mathrm{w} \%} \quad=\quad \text { solid mass concentration }\left(=\left[M_{\text {cement }}+M_{\text {dry_tailings }}\right] /\left[M_{\text {cement }}+M_{\text {dry_tailings }}+M_{\text {water }}\right]\right) \text { of the } \\
& \text { specimen }(w t \%) \text {. }
\end{aligned}
$$

The chemical shrinkage per unit mass of cement at time t $C S(t)$ is computed as:

$$
C S(t)=\frac{\Delta h(t)}{M_{c e m}}=\frac{h(t)-h\left(t_{0}=60 \mathrm{~min}\right)}{M_{c e m}}
$$

Where:

$\begin{array}{lll}C S(t) & = & \text { chemical shrinkage at time } \mathrm{t}(\mathrm{mL} / \mathrm{g} \text { cement }) . \\ h(t) & = & \text { water level in capillary tube at time } \mathrm{t}(\mathrm{mL}) .\end{array}$

\section{$4 \quad$ Experimental program}

\subsection{Verification measurements}

An initial set of chemical shrinkage experiments on Type GU neat cement pastes was carried for comparison with published data, to ensure that the correct procedures were being followed. While the ASTM test method specifies a $w / c$ ratio of 0.40 in order to minimise both bleeding and depercolation effects (ASTM, 2007), these preliminary measurements were performed on pastes with $w / c=0.35$ (as permitted in the ASTM procedure) so that the results could be compared with measurements performed by Bentz et al. (2008). One triplicate of specimens were prepared and tested (see Table 1).

Table 1 Experimental program

\begin{tabular}{llllll}
\hline Test No. & Type of Material Prepared & $\begin{array}{l}\text { Water- } \\
\text { Cement } \\
\boldsymbol{w} / \mathbf{c}\end{array}$ & $\begin{array}{l}\text { Cement } \\
\text { Content } \\
\mathbf{( w t \% )}\end{array}$ & $\begin{array}{l}\text { Solid } \\
\text { Content } \\
\mathbf{( w t \% )}\end{array}$ & Specimens \\
\hline \multicolumn{2}{l}{ Verification testing } & & & & \\
$\# 1$ & Cement paste & 0.35 & 100 & 74 & 1 triplicate \\
Main testing & & & & \\
$\# 2$ & Cement paste & 0.35 & 100 & 74 & 1 triplicate \\
$\# 3$ & Cement paste & 0.7 & 100 & 59 & 2 triplicates \\
$\# 4$ & Cement paste & 7.0 & 100 & 13 & 2 triplicates \\
$\# 5$ & Cement slurry & 13.5 & 3 & 7 & 1 triplicate \\
$\# 6$ & CMB, silica sand (SS) & 11.12 & 3 & 75 & 1 duplicate \\
$\# 7$ & CMB, Tanami tailings & 13.5 & 3 & 71.2 & 1 duplicate \\
$\# 8$ & CMB, Kanowna Belle (KB) & 0.4 & 95 & 72.43 & 1 triplicate \\
$\# 9$ & CMB, KB & 0.7 & 54.39 & 72.43 & 1 triplicate \\
$\# 10$ & CMB, KB & 7.0 & 5.439 & 72.43 & 1 triplicate \\
$\# 11$ & CMB, KB & 12.69 & 3 & 72.43 & 1 triplicate \\
\hline
\end{tabular}




\subsection{Main test program}

The samples used in the main test program (Tests 2-11, Table 1) include different neat cement pastes obtained with Type GU cement (Tests 2-5), a mixture of CMB using silica sand (Test 6), and mixtures of CMB using two different mine tailings (Tests 7-11). The material from Kanowna Belle (KB) has already been discussed. The specific gravity $\mathrm{G}_{\mathrm{s}}$ of Tanami tailings is 2.86 . The second mine tailings sample was taken from Tanami mine in Australia. The specific gravity $G_{\mathrm{s}}$ of Tanami tailings is 2.86 . For the cement pastes, four $w / c$ ratios were tested: $0.35,0.7,7$ and 13.5. Wherever possible, the same $w / c$ ratios are used for preparation of the CMB mixtures. The $w / c$ ratio of 13.5 was chosen for simulating CMB prepared with Tanami tailings, but can also be compared to $\mathrm{CMB}$ prepared with Kanowna Belle (KB) tailings $(w / c=12.69)$. The $w / c$ ratio of the CMB with silica sand $(w / c=11.12)$ was primarily chosen to match $w / c$ of the $\mathrm{CMB}$ with $\mathrm{KB}$ tailings which was a little higher $(w / c=12.69)$. It should be noted that a $w / c$ ratio of 0.4 was used instead of 0.35 for $\mathrm{CMB}$ mixtures with $\mathrm{KB}$ tailings due simply to the residual water content of $1.2 \%$ (practically fully dried). Indeed, $w / c=0.35$ required that KB tailings are completely dry, which was not the case (initial water content of 39\%). Therefore, the tailings were dried slowly at ambient air in the laboratory $\left(23 \pm 2^{\circ} \mathrm{C}\right)$ for several days.

\section{$5 \quad$ Results and discussion}

\subsection{Verification test results}

Figure 3 presents the chemical shrinkage measurements for $w / c=0.35$ of Type GU cement paste. The chemical shrinkage $C S(t)$ data are expressed as volume change $(\mathrm{mL})$ per unit mass $(\mathrm{g})$ of cement. The average temperature was $25^{\circ} \mathrm{C}$. In Figure 3, Tests $\# 1$ and $\# 2$ results were compared together and to the chemical shrinkage data published by Bentz et al. (2008) for two different types of ASTM Type I/II Portland cement pastes with the same $w / c=0.35$. These two Type I/II portland cements differ in fineness. While their chemical compositions are similar, with the exception of the coarser cement having a lower alkali content, their finenesses and particle size distributions are quite distinct. The finer cement has $25 \mu \mathrm{m}$ as its modal value, while the coarser cement has $32 \mu \mathrm{m}$ as its modal value. The average Blaine specific surface area $S_{\mathrm{m} \text {-Blaine }}$ of Type GU or I cement is about $350 \mathrm{~m}^{2} / \mathrm{kg} \pm 20$ and average particle diameter of $15 \mu \mathrm{m}$. The finer Type I/II cement has $S_{\mathrm{m} \text {-Blaine }}=380 \mathrm{~m}^{2} / \mathrm{kg}$ and average particle diameter of $11.5 \mu \mathrm{m}$ and a coarser Type I/II cement has $S_{\mathrm{m} \text {-Blaine }}=311 \mathrm{~m}^{2} / \mathrm{kg}$ and average particle diameter of $17 \mu \mathrm{m}$. It should be noted that the experimentally observed chemical shrinkage depends both on the chemical composition of the cement and its fineness (Beltzung and Wittmann, 2000; Bentz et al., 2008). Therefore, it is expected that the response of Type GU and Type I/II cements are not identical and that is exactly what is shown in Figure 3.

First, this figure clearly shows the impact of the fineness of cement on its chemical reactivity (or chemical shrinkage). It then shows that the two tests (Tests 1 and 2) on the Type GU cement gave very similar results. In addition, the results of Type GU cement pastes are slightly lower than those of Type I/II cement pastes, probably because of their different reactivity due to the difference in fineness. From this figure, it can be concluded that the ASTM C1608 (ASTM, 2007) test protocol has been followed well and that results are reliable and reproducible. 


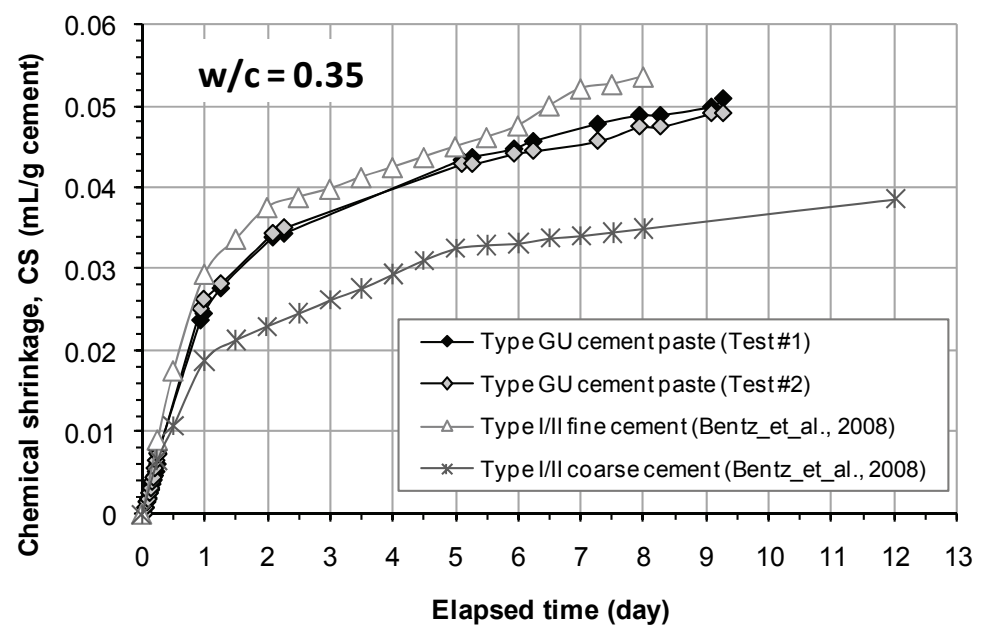

Figure 3 Chemical shrinkage at $25^{\circ} \mathrm{C}$ for $w / c=0.35$ Type GU and Type I/II cement pastes. Each curve of Type GU cement is an average of three replicate specimens

\subsection{Main test results}

\subsubsection{Effect of $w / c$ on chemical shrinkage of cement pastes}

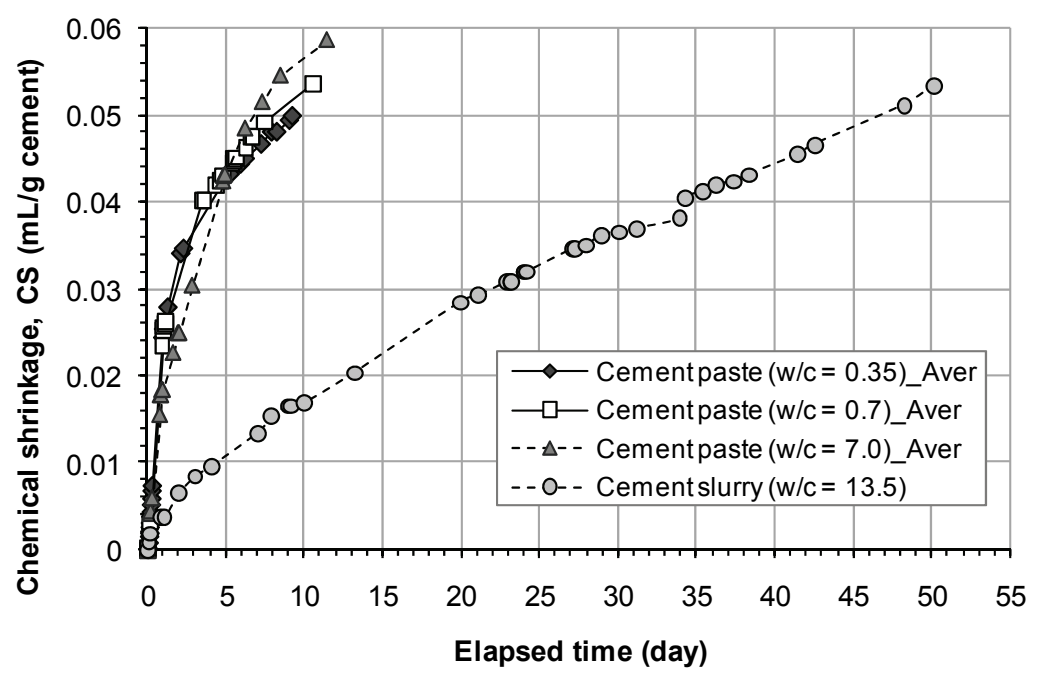

Figure 4 Chemical shrinkage at $25^{\circ} \mathrm{C}$ for $w / c=0.35,0.7,7.0$, and 13.5 cement pastes (Type GU). Each curve is an average on three replicate specimens

Figure 4 presents the evolution curves of (normalised) chemical shrinkage of Type GU cement pastes for four different $w / c$ ratios $(0.35,0.7,7.0$ and 13.5). This figure first shows that the normalised curves of chemical shrinkage of cement pastes are similar for $w / c$ between 0.35 and 0.7 , and while the curve for $w / c=7.0$ differs slightly from the previous curves.

A radically different behaviour can be seen in the curve for $w / c=13.5$ (slurry). This suggests therefore that when $w / c$ is large or very large (resulting in a greater distance between cement grains in the mix), hydration is slower (less 'efficient'), but still takes place fully anyway. This results in an almost linear trend of chemical shrinkage over time.

The very different behaviour at high $w / c$ ratios may be related to the theory proposed for $w / c>1$ cement slurries by Beltzung and Wittmann (2000), which distinguishes the phase I of cement dissolution (depending on the chemical composition and fineness of cement) followed by the phase II of chemical shrinkage (see 
Equations (4) and (5)). It is also interesting to note that even after 48 days, hydration is continuing for the $13.5 \mathrm{w} / \mathrm{c}$ ratio.

\subsubsection{Effect of $w / c$ on chemical shrinkage of cemented mine backfill}

Figure 5 presents a comparison between chemical shrinkage of cement paste and CMB prepared with KB tailings for $w / c=0.4,0.7,7.0$, and 13.5 (or 12.69 for $\mathrm{KB}$ ). The curves exhibit at least a two-slope behaviour (see Figure 5a): the initial slope corresponding to high rate of chemical shrinkage at very early age (hence, high rate of hydration), and the second slope corresponding to a slow rate of chemical shrinkage (slow rate of hydration).

The difference between the slopes of the chemical shrinkage curves of cement pastes and CMB is likely to be due to the presence of mine tailings (fillers). From this point of view, it is interesting to note that the notion of 'efficiency' of the hydration reactions (expressed in terms of $E_{\mathrm{h}}$ ) introduced by Helinski et al. (2007) is consistent and valid in concept.
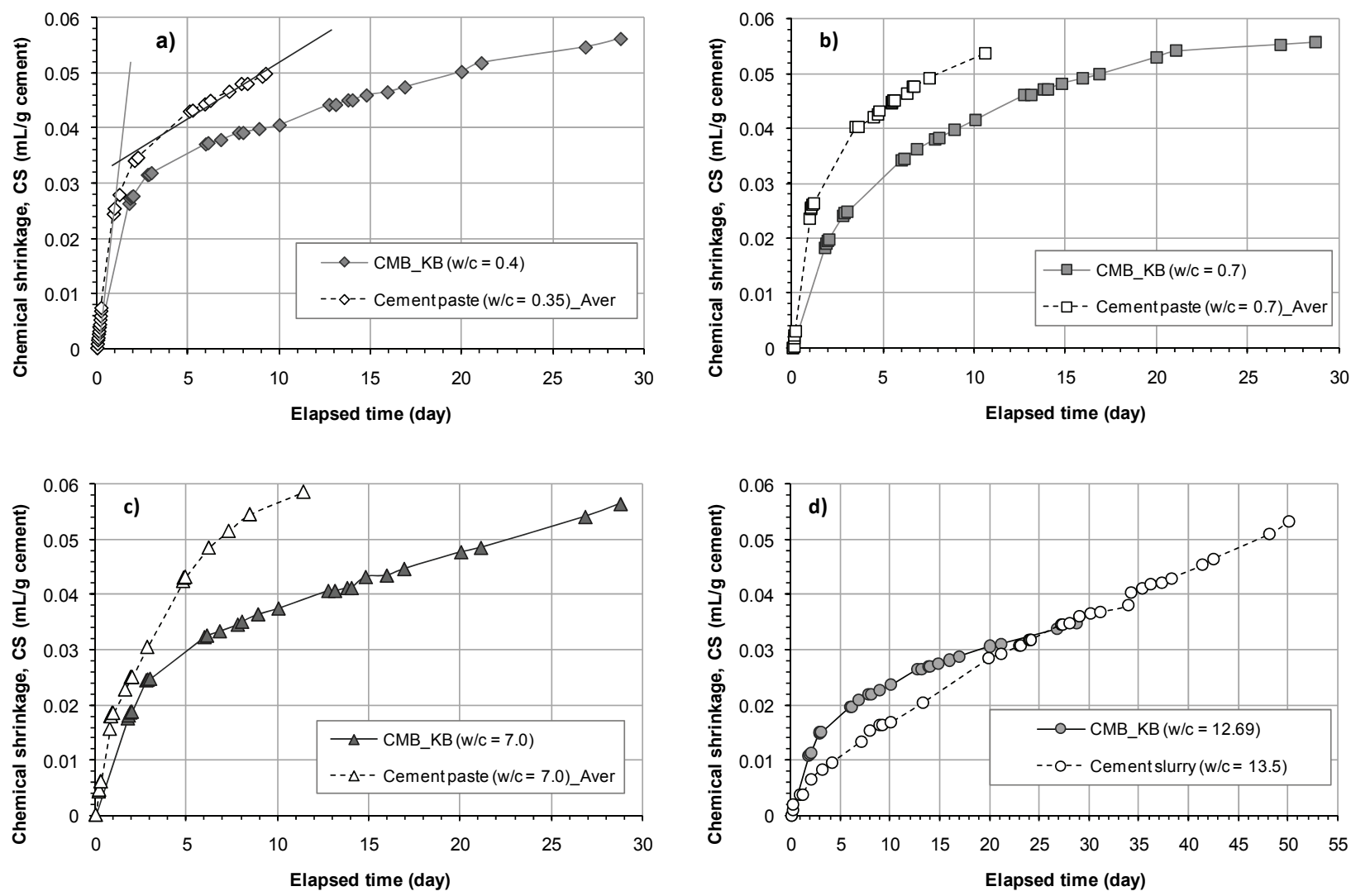

Figure 5 Comparison of chemical shrinkage at $25^{\circ} \mathrm{C}$ for cemented mine backfills and cement pastes or slurry: a) $w / c=0.35 ;$ b) $w / c=0.7$; c) $w / c=7.0$; d) $w / c=13.5$

Figure $5 \mathrm{~d}$ shows that the evolution curves of chemical shrinkage of $\mathrm{KB}$ tailings CMB $(w / c=12.69)$ and cement slurry $(w / c=13.5)$ converge after 576 hours. This same type of behaviour is also observed for the CMB made with Tanami and KB tailings (see Figure 6a). From Figure 6a, it is possible to think that the Tanami backfill curve will converge with the KB backfill curve beyond 300 hours of hydration. Figure $6 \mathrm{~b}$ shows the comparison of chemical shrinkage of KB backfill for four water-to-cement ratios: 0.4, 0.7, 7.0 and 12.69. The observations made in Figure 4 are also valid for Figure $6 b$. 

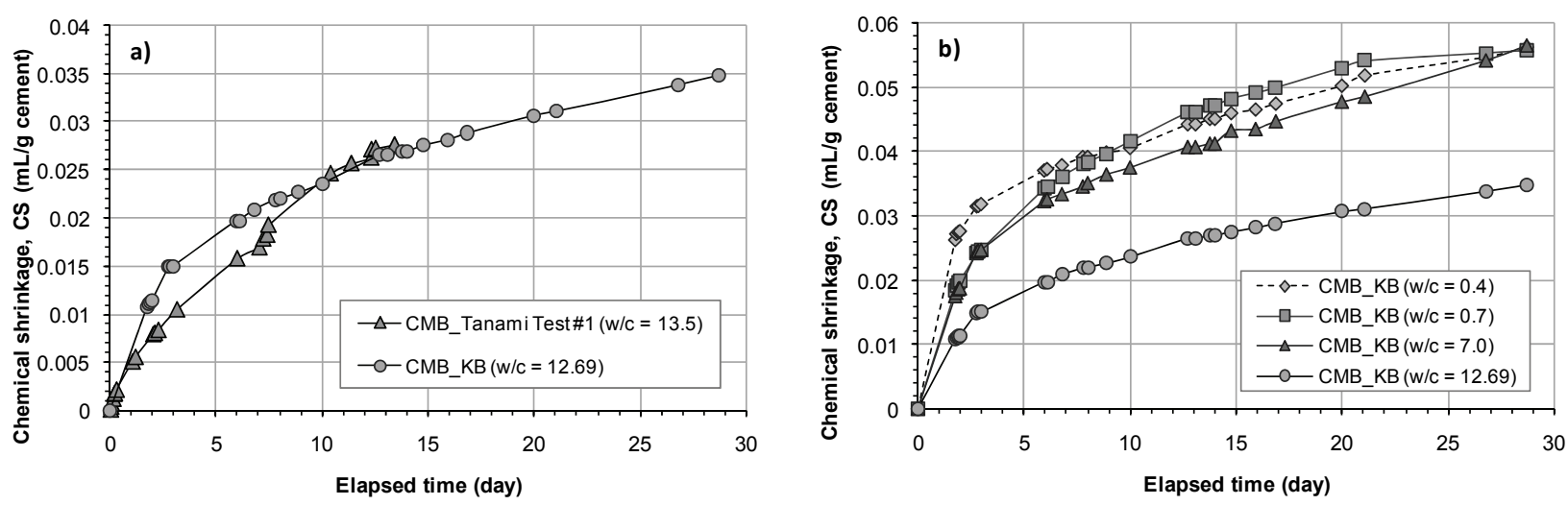

Figure 6 Comparison of chemical shrinkage at $25^{\circ} \mathrm{C}$ for cemented mine backfill: a) between Tanami backfill $(w / c=13.5)$ and KB backfill $(w / c=12.69)$, b) between KB backfill for $w / c=0.35$, 0.7, 7.0, and 12.69

\subsubsection{Effect of filler on chemical shrinkage of cemented mine backfill}

Figure 7 is a comparison between the chemical shrinkage of cemented mine backfills (Tanami and KB) and CMB-like material (cemented silica sand). Both tailings and silica sand seem to act as filler during the hydration process. From this figure, it can be seen that the grain size distribution (which is the biggest difference between silica sand and mine tailings) may play an important role during the cement hydration process. The most interesting observation is that the chemical shrinkage of Tanami backfill (Figure 7a) and KB backfill (Figure 7b) are much closer, but less than that of cemented silica sand. This figure also suggests that the larger are the solid grains (filler), the more 'efficient' are the hydration reactions, which depend on chemical composition and fineness of cement used. However, one should not confuse the efficiency of hydration reactions with a potential of good ultimate strength development. This efficiency is rather to be connected to the hydraulic activity of cement and its potential of hydration in the short term. For example, a blended binder GU/Slag would obviously be 'inefficient' in terms of short-term hydration (low short-term strength) but instead, has a strong potential for developing good long-term strength.
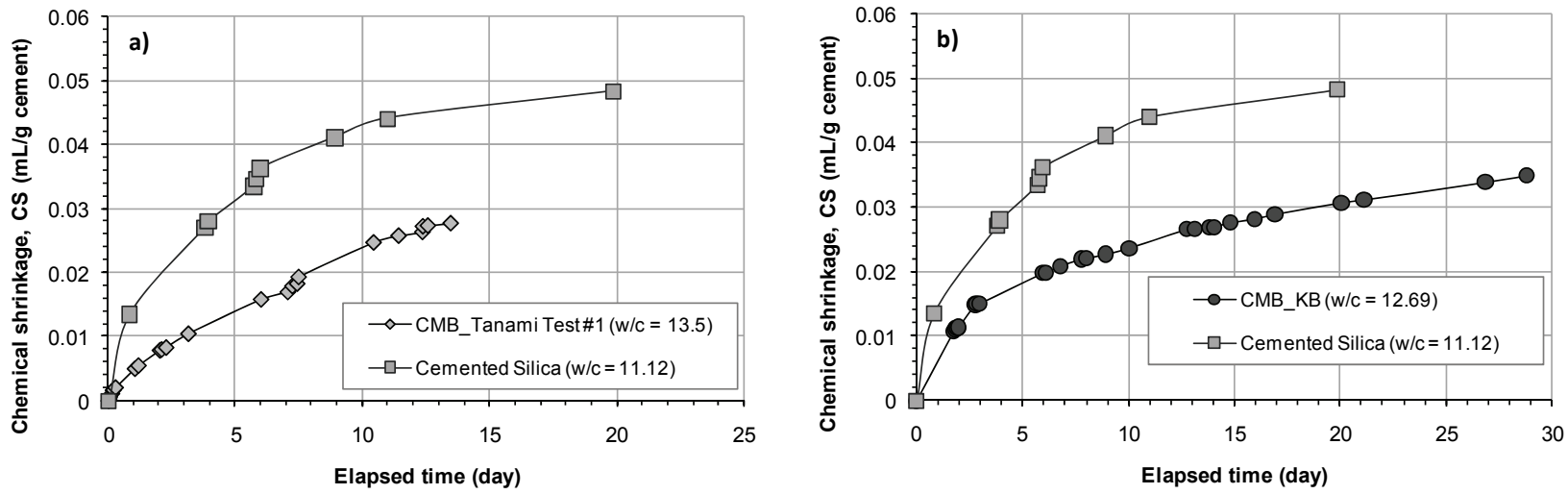

Figure 7 Evolution curves of chemical shrinkage at $25^{\circ} \mathrm{C}$ for cemented silica sand compared to: a) Tanami backfill $(w / c=13.5)$; b) KB backfill $(w / c=12.69)$

\section{Conclusion}

This paper presents preliminary results of chemical shrinkage (volume change) measurements on cemented mine backfills (CMB). The importance of chemical shrinkage in mine backfilling is that this phenomenon can cause significant reductions in excess pore water pressure during cement hydration, as demonstrated by Helinski et al. (2007). The main purpose of this study was not to link measurements of chemical shrinkage (or endogenous shrinkage) to pore water pressure reduction during early age hydration processes directly, but 
to quantify the chemical shrinkage from direct measurements. From this point of view, this work is a good contribution to understanding the short term hydration phenomena in cemented mine backfill. Indeed, it has often been anticipated that there would be little or no hydration in cemented mine backfill in the short term, simply because of the higher water-to-cement $w / c$ ratios typically used. Preliminary results from this study demonstrate the exact opposite of that. Moreover, it is not universally accepted that the chemical shrinkage actually exists in the case of high $w / c$ ratios and again this study provides some insight on this aspect. This study showed that the effectiveness of short-term hydration decreased when solid is added to cement (sand or tailings) and when the $w / c$ ratios became higher.

\section{Acknowledgements}

The authors wish to thank the project sponsors Panoramic Resources, Barrick, and BHP Billiton for their support of this research. The first author conducted this work when he was on sabbatical leave at the School of Civil and Resource Engineering, The University of Western Australia. The authors would also like to acknowledge Binaya Bhattarai, senior engineer (Soils Laboratory) and Claire Bearman, soils technician, for their valuable support.

\section{References}

Acker, P. (2004) Swelling, shrinkage and creep: a mechanical approach to cement hydration, Materials and Structures/Concrete Science and Engineering, Vol. 37, pp. 237-243.

ASTM C1608 (2007) Test Method for Chemical Shrinkage of Hydraulic Cement Paste, The American Society of Testing and Materials, USA.

Belem, T. and Benzaazoua, M. (2007) Underground mine paste backfill technology: applications and design methods, Geotechnical and Geological Engineering, Vol. 26(2), pp. 147-174.

Beltzung, F. and Wittmann, F.H. (2000) Dissolution of cement and early chemical shrinkage of cement paste, in Proceedings RILEM symposium on shrinkage of concrete (Shrinkage 2000), V. Baroghel-Bouny and P. Aïtcin (eds), Paris: RILEM Publications; 2000, pp. 91-97.

Bensted, J. (1983) Early hydration of Portland cement - Effect of water/cement ratio, Cement and Concrete Research, Vol. 13, pp. 493-498.

Bentz, D.P., Sant, G. and Weiss, J. (2008) Early-Age Properties of Cement-Based Materials, Influence of Cement Fineness, Journal of Materials in Civil Engineering, Vol. 20(7), pp. 502-508.

Benzaazoua, M., Fall, M. and Belem, T. (2004) A contribution to understanding the hardening process of cemented pastefill, Minerals Engineering, Vol. 17(2), pp. 141-152.

Boivin, S., Acker, P., Rigaud, S. and Clavaud, B. (1998) Experimental assessment of chemical shrinkage of hydrating cement paste, in Proceedings of the International Workshop on Autogenous Shrinkage of Concrete (Autoshrink '98), E.I. Tazawa (ed), Londres E\&FN Spon, pp. 81-92.

Bonett, A. and Pafitis, D. (1996) Getting to the Root of Gas Migration, Oilfield Review, Spring 1996, Vol. 8, No. 1, pp. 36-49.

Bouasker, M., Mounanga, P., Turcry, P., Loukili, A. and Khelidj, A. (2008) Chemical shrinkage of cement pastes and mortars at very early age: Effect of limestone filler and granular inclusions, Cement and Concrete Composites, Vol. 30, pp. 13-22.

Buil, M. (1979) Studies of the shrinkage of hardening cement paste, (in French), D.Eng. thesis, Rapport de recherche LPC No. 92, Laboratoire Central des Ponts et Chaussées, Paris.

Chenevert, M.E. and Shrestha, B.K. (1991) Chemical shrinkage properties of oilfield cements, Journal of SPE Drilling Engineering, Vol. 6(1), pp. 37-43.

Cooke, C.E. Jr., Kluck, M.P. and Medrano, R. (1983) Field measurements of annular pressure and temperature during primary cementing, Journal of Petroleum Technology, Vol. 35(8), pp. 1429-1438.

Czernin, W. (1962) Cement Chemistry and Physics for Civil Engineers, Crosby Lockwood \& Son Ltd., London, pp. $61-65$.

Damidot, D. and Nonat, A. (1991) Investigations of the C3S hydration process during the first hours of hydration, RILEM Proceedings 16 on Hydration and Setting of Cements, Dijon, France.

Felman, R.F. and Sereda, P.J. (1968) Matériaux et Constructions, Vol. 1, 509 p.

Fourie, A., Helinski, M. and Fahey, M. (2006) Filling the gap - a geomechanics perspective, Australian Centre for Geomechanics Newsletter 26, Perth, Australia, pp. 1-4.

Garcia-Boivin, S. (1999) Retrait au jeune âge du béton: Développement d'une méthode expérimentale et contribution à l'analyse physique du retrait endogène, Ph.D. thesis, Paris, ENPC; 1999 [in French].

Geiker, M. (1983) Measurements of chemical shrinkage and a systematic evaluation of hydration curves by means of the dispersion model, Ph.D. Thesis, Technical University of Denmark. 
Geiker, M. and Knudsen, T. (1982) Chemical shrinkage of Portland cement pastes, Cement and Concrete Research, Vol. 12(5), pp. 603-610.

Grabinsky, M. and Simms, P. (2006) Self-desiccation of cemented paste fill and implications for mine design, in Proceedings Ninth International Seminar on Paste Thickened Tailings, Limerick, Ireland, 3-7 April 2006, R.J. Jewell, S. Lawson, P. Newman (eds), Australian Centre for Geomechanics, Perth, Australia, pp. 323-332.

Hansen, P.F., Jessing, J., Mønsted, K. and Trudsø, E. (1968) The influence of the temperature on chemical shrinkage at early stages, in Proceedings 5th International Symposium on Chemistry of Cement, Tokyo, Vol. 3, pp. 503-521.

Helinski, M., Fourie, A.B., Fahey, F. and Ismail, M. (2007) Assessment of the self-desiccation process in cemented mine backfills, Canadian Geotechnical Journal, Vol. 44(10), pp. 1148-1156.

Illiston, J.M., Dinwoodie, J.M. and Smith, A.A. (1979) Concrete, timber and metals : the nature and behaviour of structural materials, Van Nostrand Reinhold Company, New York, 663 p.

Justnes, H., Clemmens, F., Depuydt, P., Van Gemert, D. and Sellevold, E.J. (2000) Correlating the deviation point between external and total chemical shrinkage with the setting time and other characteristics of hydrating cement paste, in Proceedings RILEM symposium on shrinkage of concrete (Shrinkage 2000), V. Baroghel-Bouny and P. Aïtcin (eds) Paris: RILEM Publications, pp. 57-73.

Justnes, H., Reyniers, B., Van Loo, D. and Sellevold, E.J. (1994) An evaluation of methods for measuring chemical shrinkage of cementitious paste, Nordic Concrete Research, Vol. 14, pp. 45-61.

Knudsen, T. and Geiker, M. (1982) Chemical Shrinkage as an Indicator of the Stage of Hardening, International Conference on Concrete of Early Ages, Paris, ENPC Press, Vol. I, pp. 163-165.

Levine, D.C., Thomas, E.W. and Bezner, H.P. (1979) Annular gas flow after cementing: A look at practical solutions, Paper SPE 8255 presented at the 1979 SPE Annual Technical Conference and Exhibition, Las Vegas, September 23-26, American Institute of Mining, Metallurgical, and Petroleum Engineers, Inc.

Lide, D.R. (1997) Handbook of Chemistry and Physics, New York, CRC Press, 78th edition.

Parrott, L.J., Geiker, M., Gutteridge, W.A. and Killoh, D., (1990) Monitoring Portland Cement Hydration: Comparison of Methods, Cement and Concrete Research, Vol. 20, pp. 919-926.

Powers, T.C. (1935) Absorption of water by Portland cement paste during the hardening process, Industrial and Engineering Chemistry; Vol. 27(7), pp. 790-794.

Powers, T.C. (1968) The Properties of Fresh Concrete, John Wiley and Sons, Inc., New York, 664 p.

Powers, T.C. and Brownyard, T.L. (1948) Studies on the Physical Properties of Hardened Portland Cement Paste, PCA Bulletin 22, Chicago, Illinois.

Sant, G., Lura, P. and Weiss, J. (2006) Measurement of Volume Change in Cementitious Materials at Early Ages: Review of Testing Protocols and Interpretation of Results, Transportation Research Record: Journal of the Transportation Research Board, No. 1979, Transportation Research Board of the National Academies, Washington, D.C., 2006, pp. 21-29.

Skoblinskaya, N.N. and Krasilniko, K.J. (1975) Changes in crystal structure of ettingite on dehydration 1, Cement and Concrete Research, Vol. 5, pp. 381-394.

Witteman, M. and Simms, O. (2010) Hydraulic response of cemented paste backfill during and after hydration, in Proceedings Thirteenth International Seminar on Paste and Thickened Tailings (Paste2010), R. Jewell and A.B. Fourie (eds), 3-6 May 2010, Toronto, Canada, Australian Centre for Geomechanics, Perth, pp. 199-208. 